\title{
Estimation of reference intervals of insulin resistance (HOMA), insulin sensitivity (Matsuda), and insulin secretion sensitivity indices (ISSI-2) in Polish young people
}

\author{
Sylwia Płaczkowska' ${ }^{1, A-D, F \oplus}$, Lilla Pawlik-Sobecka ${ }^{2, B-F \oplus}$, Izabela Kokot ${ }^{2, B, E \oplus}$, Agnieszka Piwowar ${ }^{3, A-F \oplus ~}$
}

${ }^{1}$ Diagnostics Laboratory for Teaching and Research, Faculty of Pharmacy with the Division of Laboratory Diagnostics, Medical University, Wroclaw, Poland

${ }^{2}$ Department of Laboratory Diagnostics, Faculty of Pharmacy with the Division of Laboratory Diagnostics, Medical University, Wroclaw, Poland

${ }^{3}$ Department of Toxicology, Faculty of Pharmacy with the Division of Laboratory Diagnostics, Medical University, Wroclaw, Poland

A - Research concept and design, B - Collection and/or assembly of data, C - Data analysis and interpretation, $D$ - Writing the article, E - Critical revision of the article, F - Final approval of article

Płaczkowska S, Pawlik-Sobecka L, Kokot I, Piwowar A. Estimation of reference intervals of insulin resistance (HOMA), insulin sensitivity (Matsuda), and insulin secretion sensitivity indices (ISSI-2) in Polish young people. Ann Agric Environ Med. 2020; 27(2): 248-254. doi: 10.26444/aaem/109225

\begin{abstract}
Introduction. Insulin resistance is becoming an increasingly widespread problem worldwide. For its determination indirect indices of insulin resistance or insulin sensitivity have used. Those indices based on simultaneous measurements of blood glucose and insulin concentrations under fasting conditions or during the Oral Glucose Tolerance Test.

Objective. The aim of the study was to estimate reliable reference values for the indices used in insulin resistance diagnosis. Materials and method. 191 selected participants, aged 18-31, were enrolled into the reference population. 130 participants from the reference population with fasting glucose $\leq 5.5 \mathrm{mmol} / \mathrm{L}, \mathrm{BMl}<25 \mathrm{~kg} / \mathrm{m}^{2}$, and without metabolic syndrome, were finally included in the reference group. The following insulin resistance indices were calculated: HOMA1-IR, HOMA2, HOMA2 from C-peptide, QUICKI, Matsuda Index and Insulin Secretion-Sensitive Index-2. Determination of reference intervals for indirect indices of insulin resistance was conducted in accordance with the C28-A3 procedure recommended by the Clinical \& Laboratory Standards Institute (CLSI).

Results. The reference intervals for indirect insulin resistance indices examined according to CLSI protocol were: $\leq 4.00$, $\leq 2.27, \leq 4.10, \geq 0.31$ for HOMA1-IR, HOMA2, HOMA2 C-pep., and QUICKI, respectively. For insulin sensitivity, the value of the Matsuda Index was established as $\geq 3.19$ and for beta cell pancreatic function ISSI- 2 as $\geq 206$.

Conclusions. Establishing a reference intervals for these indices enable the proper identification and differentiation of the types of insulin resistance in particular populations. The early detection of metabolic disorders allows for introduction of effective preventive action.
\end{abstract}

\section{Key words}

insulin resistance, young adult, Oral Glucose Tolerance Test, Reference Interval

\section{INTRODUCTION}

Insulin resistance (IR) is defined as an impaired glucose homeostasis, in the course of which the sensitivity of target tissues to insulin is decreased. This phenomenon affects mainly the skeletal muscles (peripheral IR) and/or liver and adipose tissue cells (central IR) [1]. Current studies indicate that insulin resistance affects large population groups of working-age, and is particularly associated with overweight and obesity [2,3], However, an increasing number of reports show that insulin resistance may also affect young people with normal body weight, with no overt metabolic disorders or positive family history of metabolic disturbances [4].

Even though intravenous glucose and insulin infusion (i.e. the glucose clamp test) is still referred to as the "gold

Address for correspondence: Lilla Pawlik-Sobecka, Department of Laboratory Diagnostics, Faculty of Pharmacy with the Division of Laboratory Diagnostics, Wroclaw Medical University, Borowska 211a, 50-556, Wrocław, Poland

E-mail: Iilla.pawlik-sobecka@umed.wroc.pl

Received: 27.01.2019; accepted: 07.05.2019; first published: 18.06.2019 standard," and the intravenous glucose tolerance test is recommended, these methods are very rarely used because of their high onerousness for the patient [5]. For this reason, in clinical practice, indirect indices of insulin resistance or insulin sensitivity have been used, based on simultaneous measurements of blood glucose (FG) and insulin concentrations under fasting conditions or after oral glucose administration - Oral Glucose Tolerance Test (OGTT) [6]. The most widely used method for IR recognition is the measurement of fasting glucose and insulin concentration, followed by the calculation of appropriate indicators according to the relevant formulas, such as the Insulin Glucose Index, or indices derived from Homeostasis Model Assessment (HOMA) [7]. Detecting abnormalities in these parameters may be the first sign of metabolic disturbances, especially impaired glucose homeostasis, and an indication for further detailed diagnosis by performing additional tests (i.e. OGTT). Measurement of glucose and insulin during the oral glucose tolerance test and calculation of the Matsuda Index enables estimation of the ability to 
utilize large amounts of exogenous glucose by peripheral tissues, mainly muscle cells, whereas the Insulin SecretionSensitive Index-2 (ISSI-2) measures the ability of $\beta$-cells to compensate for changes in whole-body insulin sensitivity by a change in insulin secretion [1]. All these indices enable the identification and differentiation of types of insulin resistance. Indices calculated in the fasting state describe the balance between liver production of glucose and pancreatic insulin under this condition, while the ability of glucose uptake through muscle tissue, and the ability of beta cells to compensate for peripheral insulin resistance, are described by indicators determined by a functional test (OGTT), which mimics the post-prandial state [8].

In the scientific literature, the reference values for indirect indices used for insulin resistance diagnosis differ according to the studied population, age, gender and ethnicity, as well as the laboratory methods used for glucose and insulin concentration determination $[3,9,10]$. Especially confusing and ambiguous is IR recognition concerning young people, on whom such studies are not routinely performed. Very little data is available on either the prevalence of insulin resistance or cut-off values for the above-mentioned indices for the young Polish population $[11,12]$. The most common values of insulin resistance indices used for identification of these disturbances extant in the scientific literature are established as the upper 75 th (95th) or below the 25th (5th) percentile values observed in different analysed populations. This is not exactly in accordance with current laboratory guidelines, but is very widely applied in epidemiological studies $[1,10,13]$. For this reason, it is important to define reliable reference intervals (RIs) for the indices used in insulin resistance diagnosis in this age group, which may enable the early detection of metabolic disorders and the introduction of preventive action.

\section{OBJECTIVE}

The aim of this study was to estimate the reference intervals for the most common insulin resistance indices, such as HOMA1-IR, HOMA2 and HOMA2 C-pep. [7], QUICKI [14], Matsuda Index [15] and ISSI-2 [16], using the standard method based on the procedure of determining reference interval (RI) recommended by the Clinical and Laboratory Standards Institute (CLSI) in document C28-A3 from 2008 [17]. Moreover, the cut-off values of the 25 th or 75 th percentile, respectively, for these indices were established in the same study group in order to facilitate comparison of the analyzed indices with other studies and literature data.

\section{MATERIALS AND METHOD}

349 participants (260 females and 89 males) in an apparently good state of health were initially enrolled in the study "Determination of the reference intervals for the HOMA Index, Matsuda Index and Disposition Index in young people", financed by a grant from Wroclaw Medical University and conducted in 2016-2017 [18].

Participants, the majority of whom were current or former university students, were given information about recruitment from advertisements distributed at the universities of Wroclaw. After being informed about the purpose and procedure of the study, all took part in the research voluntarily and gave their written consent. The study protocol was approved by the Bioethics Committee of Wroclaw Medical University (537/2018). The criteria for inclusion in the study were: age 18-31, willingness to participate in the study and good overall health. Exclusion criteria were a history of diabetes, liver or kidney failure, past cancer, acute infections during the 2 weeks preceding the study, or taking anti-allergic drugs during the 3 months preceding the study, as reported by the participants. Before the study, all participants completed a specific author's questionnaire, in which data about smoking status, physical activity, health condition (subjectively assessed), current medication intake and family history of metabolic disorders were collected. After completing the questionnaire, participants underwent a physical examination which included anthropometric measurements, such as height, weight, and waist circumference.

Although the current study is generally based on the same set of participants as a previous study [18], the aim and results take into consideration a completely different research issue. The research problem presented in this study has been resolved strictly in accordance with global guidelines, and applies only to the participants who agreed to perform OGTT, which was obligatory for the Matsuda Index and ISSI-2 calculations. Among the total number of 349 participants, 191 (138 females and 53 males) performed OGTT, and only these participants were selected as the reference population in the presented study. Before fasting blood samples were taken and OGTT performed, each participant had their glucose concentration in capillary blood checked by a glucometer, and further collection of venous blood was performed if the capillary glucose was $\leq 7.0 \mathrm{mmol} / \mathrm{L}$. Three-point OGTT was then performed with 75 glucose ingestion in $250 \mathrm{ml}$ of water. Finally, 130 participants (106 females and 24 males) from the reference population with fasting glucose $\leq 5.5 \mathrm{mmol} / \mathrm{L}$, $\mathrm{BMI}<25 \mathrm{~kg} / \mathrm{m}^{2}$, and without metabolic syndrome diagnosis, were included in the reference group. Venous blood samples were drawn from each participant using the S-Monovette system (Sarstedt, Nümbrecht, Germany) in the fasting state (0' start point) at 60 th $\mathrm{min}$. (middle point) and 120 th $\mathrm{min}$. (end point) during OGTT and placed into 2 tubes, the first one containing a clotting activator and the second containing an anticoagulant (K3EDTA), to obtain serum and plasma, respectively.

At all study points, plasma glucose was determined by the GOD/POD method (Thermo Electron Oy, Vantaa, Finland). Lipid parameters: total cholesterol (TC) by the CHO/POD method (DiaSys, Holzheim, Germany), highdensity lipoprotein (HDL-C), by the AB-Wako method (DiaSys, Holzheim, Germany), triglycerides (TG) by the GPO/POD method (DiaSys, Holzheim, Germany) in the blood serum were determined in the fasting state. All biochemical parameters were measured using the Konelab 20i (ThermoScientific, Vantaa, Finland) biochemical analyser. Intra- and inter-assay coefficients of variation for FG were $1.13 \%$ and $1.99 \%$, for TC $1.72 \%$ and $2.27 \%$, for HDL-C $1.33 \%$ and $2.42 \%$, for TG $1.74 \%$ and $4.08 \%$, respectively. Lowdensity lipoprotein (LDL-C) was estimated by the Friedewald equation. Insulin at all OGTT points was determined by the enzyme-linked immunosorbent assay (ELISA), using a DRG Instruments GmbH (Marburg, Germany) reagent kit (standards calibrated against international WHO approved 
reference material NIBSC 66/304). Serum C-peptide in the fasting state was determined by the enzyme-linked immunosorbent assay (ELISA), using a DRG Instruments $\mathrm{GmbH}$ (Marburg, Germany) reagent kit (standards are calibrated against international WHO approved reference material IRR C-peptide, code 84/510). Multiscan GO microplate reader (Thermo Fisher Scientific, Oy, Finland) was used for insulin and C-peptide measurement, and intra- and inter-assay coefficients of variation for insulin and C-peptide were $5.5 \%, 8.7 \%$ and $7.1 \%, 11.4 \%$, respectively. On the basis of glucose and insulin concentrations under fasting conditions, the following indices were calculated: HOMA1-IR, HOMA2, HOMA2 from C-peptide, QUICKI, as described previously [18]. Moreover, Matsuda Index and ISSI-2 were calculated on the basis of OGTT glucose and insulin results by on-line calculator [18] and mathematical formula [16], respectively. Determination of reference limits for selected indirect indices of insulin resistance was conducted in accordance with the procedure recommended by CLSI and published in the
C28-A3 document in 2008 [17]. The process for establishing reference ranges was carried out in accordance with the protocol shown in Figure 1.

Even though protocol C28-A3 is mainly dedicated to 2 -sided reference interval determination, it was decided to establish in this study 1-sided reference limits for the indirect insulin resistance indices analyzed. In the authors' opinion, this is a more appropriate goal for clinical practice purposes, and although it is less frequently used, this method is in line with C28-A3 protocol.

Statistical analysis. The normality of the anthropometric, clinical and biochemical parameters in the male and female groups was checked by the Shapiro-Wilk test. Based on the results, U Mann-Whitney test was applied for comparison of these parameters between females and males. The Reed test was applied to truncated reference values from outliers, but none were revealed. The one sided reference limits for HOMA1-IR, HOMA2, HOMA2 C-peptide as 95th

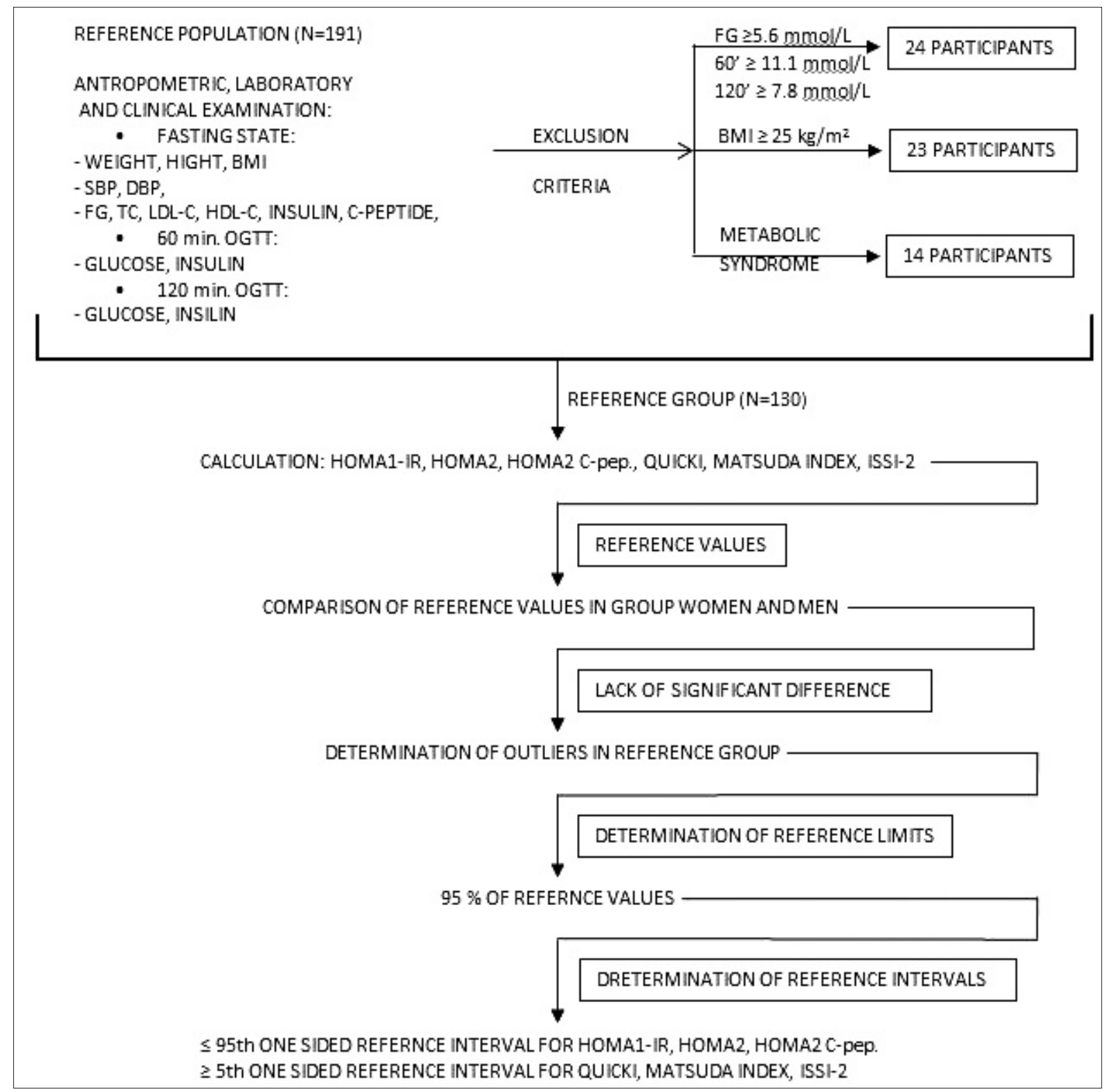

Figure 1. Flowchart of study in accordance with the procedure reccomended by CLSI published in the C28-A3. IDF 2009 definition of Metabolic Syndrome were applied [33]. SBP - Systolic Blood Pressure, DBP - Diastolic Blood Pressure, FG - Fasting Glucose, BMI - Body Mass Index 
percentile with 95\% CI were established, when for QUICKI, Matsuda Index and ISSI-2 the one sided reference limit as the 5 th percentile with $95 \%$ CI were established. This procedure was in accordance with CLSI protocol and carried out using the MedCalc 18.6 applications (Ostende, Belgium).

\section{RESULTS}

The results of the anthropometric, clinical and biochemical parameters of the reference group, with comparative analysis between females and males, are presented as medians with a 25-75 percentile range (Q1-Q3) in Table 1 . When developing the research plan, it was not assumed that the participants were divided into groups with relation to gender, because there was no information on the differences in values of insulin resistance indicators in the available literature. Moreover, the values for glucose concentration, BMI and metabolic syndrome considerd in the exclusion criteria were the same for males and females. Nonetheless, analysis results revealed physiological differences in values of waist circumference and HDL cholesterol between males and females. Moreover, levels of BMI, SBP, FG and TG were significantly higher in males compared to females, while glucose and insulin concentration at the 120th minute of OGTT was higher in females (Tab. 1). However, no significant differences were observed for the analyzed insulin resistance, insulin sensitivity or insulin secretion-sensitivity indices. Due to the absence of significant differences between females and males for comparison values, it was possible to designate the RIs for the analyzed indices, taking into account the fact that the whole reference group consisted of 130 participants without gender partitioning. Table 2 shows the 5th, 25th, 50 th, 75 th and 95 th percentiles for analyzed indices. Values were established of 1-sided reference intervals, according CLSI as equal and lower than 95th percentile (number of participants: 123) for all HOMA indices, and equal and higher than the 5th percentile (number of participants: 124) for QUICKI, Matsuda and ISSI-2 indices. The 1-sided reference limits for the insulin resistance indices were: $\leq 4.00, \leq 2.27$, $\leq 4.10, \geq 0.31$ for HOMA1-IR, HOMA2, HOMA2 C-pep., and QUICKI, respectively, when for insulin sensitivity Matsuda Index this value was established as $\geq 3.19$ and for beta cell pancreatic function ISSI- 2 as $\geq 206$. The cut-off values for insulin resistance recognition established were: $>2.78,>1.72$, $>2.63,<0.33$ for HOMA1-IR, HOMA2, HOMA2 C-pep., QUICKI, respectively and $<4.31$ and $<261$ for Matsuda and ISSI-2, respectively. The values of the upper 75 th percentile (number of participants: 97) for HOMA indices and below the 25th percentile (number of participants: 32) for QUICKI, Matsuda and ISSI-2 indices are presented for comparison with results obtained in Polish young adults with data from the other publications in which such values are commonly used for IR recognition (Tab. 2).

\section{DISCUSSION}

Insulin resistance indices are useful not only for IR recognition in high-risk individuals, but also in apparently healthy people, especially those with normal or near-normal glycaemia, as shown by long-term epidemiological evidence. Identification of insulin-resistant people with a significantly
Table 1. Anthropometric, clinical and biochemical characteristics of the reference group with regard to values comparison between females and males

\begin{tabular}{|c|c|c|c|c|}
\hline \multirow[b]{2}{*}{ Parameters } & \multicolumn{3}{|c|}{ Reference population } & \multirow[b]{2}{*}{$\begin{array}{c}\mathrm{P} \\
\text { for Females } \\
\text { and Males } \\
\text { comparison }\end{array}$} \\
\hline & $\begin{array}{c}\text { All } \\
\text { participants } \\
(\mathrm{n}=130) \\
\text { median } \\
\text { Q1-Q3 }\end{array}$ & $\begin{array}{c}\text { Females } \\
(\mathrm{n}=106) \\
\text { median } \\
\text { Q1-Q3 }\end{array}$ & $\begin{array}{c}\text { Males } \\
(\mathrm{n}=24) \\
\text { median } \\
\text { Q1-Q3 }\end{array}$ & \\
\hline $\begin{array}{l}\text { Waist circumference } \\
{[\mathrm{cm}]}\end{array}$ & $\begin{array}{c}74 \\
70-81\end{array}$ & $\begin{array}{c}73 \\
69-79\end{array}$ & $\begin{array}{c}81 \\
75-88\end{array}$ & $<0.001$ \\
\hline $\begin{array}{l}\text { BMI } \\
{\left[\mathrm{kg} / \mathrm{m}^{2}\right]}\end{array}$ & $\begin{array}{c}20.8 \\
19.6-22.9\end{array}$ & $\begin{array}{c}20.5 \\
19.5-21.9\end{array}$ & $\begin{array}{c}23.1 \\
20.4-23.7\end{array}$ & 0.002 \\
\hline $\begin{array}{l}\text { Systolic Blood Pressure } \\
{[\mathrm{mmHg}]}\end{array}$ & $\begin{array}{c}112 \\
108-120\end{array}$ & $\begin{array}{c}110 \\
108-120\end{array}$ & $\begin{array}{c}114 \\
110-126\end{array}$ & 0.035 \\
\hline $\begin{array}{l}\text { Diastolic Blood Pressure } \\
{[\mathrm{mmHg}]}\end{array}$ & $\begin{array}{c}75 \\
70-79 \\
\end{array}$ & $\begin{array}{c}73 \\
69-79 \\
\end{array}$ & $\begin{array}{c}75 \\
71-80 \\
\end{array}$ & 0.096 \\
\hline $\begin{array}{l}\text { Glucose 0' OGTT } \\
{[\mathrm{mmol} / \mathrm{L}]}\end{array}$ & $\begin{array}{c}4.9 \\
4.6-5.2\end{array}$ & $\begin{array}{c}4.9 \\
4.6-5.1\end{array}$ & $\begin{array}{c}5.1 \\
4.9-5.3\end{array}$ & 0.001 \\
\hline $\begin{array}{l}\text { Glucose } 60^{\prime} \text { OGTT } \\
{[\mathrm{mmol} / \mathrm{L}]}\end{array}$ & $\begin{array}{c}5.1 \\
4.2-6.2 \\
\end{array}$ & $\begin{array}{c}5.0 \\
4.1-5.9 \\
\end{array}$ & $\begin{array}{c}5.2 \\
4.9-6.7 \\
\end{array}$ & 0.068 \\
\hline $\begin{array}{l}\text { Glucose } 120^{\prime} \text { OGTT } \\
{[\mathrm{mmol} / \mathrm{L}]}\end{array}$ & $\begin{array}{c}4.8 \\
4.1-5.6 \\
\end{array}$ & $\begin{array}{c}4.8 \\
4.1-5.7 \\
\end{array}$ & $\begin{array}{c}4.5 \\
3.9-5.3\end{array}$ & 0.0124 \\
\hline $\begin{array}{l}\text { Total cholesterol } \\
{[\mathrm{mmol} / \mathrm{L}]}\end{array}$ & $\begin{array}{c}4.1 \\
3.7-4.7\end{array}$ & $\begin{array}{c}4.1 \\
3.7-4.6\end{array}$ & $\begin{array}{c}4.2 \\
3.7-4.9\end{array}$ & 0.640 \\
\hline $\begin{array}{l}\text { HDL-cholesterol } \\
{[\mathrm{mmol} / \mathrm{L}]}\end{array}$ & $\begin{array}{c}1.4 \\
1.3-1.6 \\
\end{array}$ & $\begin{array}{c}1.5 \\
1.3-1.7 \\
\end{array}$ & $\begin{array}{c}1.3 \\
1.1-1.4 \\
\end{array}$ & 0.001 \\
\hline $\begin{array}{l}\text { Triglycerides } \\
{[\mathrm{mmol} / \mathrm{L}]}\end{array}$ & $\begin{array}{c}0.74 \\
0.57-1.04 \\
\end{array}$ & $\begin{array}{c}0.71 \\
0.54-1.00 \\
\end{array}$ & $\begin{array}{c}0.99 \\
0.69-1.12 \\
\end{array}$ & 0.019 \\
\hline $\begin{array}{l}\text { Insulin } 0^{\prime} \\
{[\mu \mathrm{U} / \mathrm{mL}]}\end{array}$ & $\begin{array}{c}10.68 \\
8.90-13.40\end{array}$ & $\begin{array}{c}10.90 \\
9.15-13.41 \\
\end{array}$ & $\begin{array}{c}9.97 \\
8.48-12.13 \\
\end{array}$ & 0.273 \\
\hline $\begin{array}{l}\text { Insulin 60' } \\
{[\mu \mathrm{U} / \mathrm{mL}]}\end{array}$ & $\begin{array}{c}51.60 \\
33.74- \\
76.11 \\
\end{array}$ & $\begin{array}{c}51.90 \\
34.50- \\
78.00\end{array}$ & $\begin{array}{c}51.03 \\
33.10- \\
67.15\end{array}$ & 0.817 \\
\hline $\begin{array}{l}\text { Insulin } 120^{\prime} \\
{[\mu \mathrm{U} / \mathrm{mL}]}\end{array}$ & $\begin{array}{c}39.94 \\
26.00- \\
53.42\end{array}$ & $\begin{array}{c}43.67 \\
26.70- \\
54.95\end{array}$ & $\begin{array}{c}29.58 \\
18.50- \\
38.65\end{array}$ & 0.003 \\
\hline $\begin{array}{l}\text { C-peptide } \\
{[\mathrm{ng} / \mathrm{mL}]}\end{array}$ & $\begin{array}{c}2.86 \\
2.21-3.72 \\
\end{array}$ & $\begin{array}{c}2.88 \\
2.22-3.79 \\
\end{array}$ & $\begin{array}{c}2.75 \\
1.98-3.40\end{array}$ & 0.442 \\
\hline HOMA1-IR & $\begin{array}{c}2.31 \\
2.21-2.46 \\
\end{array}$ & $\begin{array}{c}2.31 \\
1.85-2.86 \\
\end{array}$ & $\begin{array}{c}2.33 \\
1.82-2.68 \\
\end{array}$ & 0.0758 \\
\hline HOMA2 & $\begin{array}{c}1.37 \\
1.30-1.43 \\
\end{array}$ & $\begin{array}{c}1.39 \\
1.16-1.73 \\
\end{array}$ & $\begin{array}{c}1.32 \\
1.10-1.62 \\
\end{array}$ & 0.544 \\
\hline HOMA2 C-pep. & $\begin{array}{c}1.98 \\
1.88-2.18 \\
\end{array}$ & $\begin{array}{c}2.01 \\
1.55-2.71 \\
\end{array}$ & $\begin{array}{c}2.03 \\
1.46-2.53 \\
\end{array}$ & 0.763 \\
\hline QUICKI & $\begin{array}{c}0.34 \\
0.33-0.34\end{array}$ & $\begin{array}{c}0.34 \\
0.33-0.35 \\
\end{array}$ & $\begin{array}{c}0.34 \\
0.33-0.35 \\
\end{array}$ & 0.757 \\
\hline Matsuda Index & $\begin{array}{c}6.00 \\
5.06-6.12 \\
\end{array}$ & $\begin{array}{c}5.38 \\
4.27-7.66 \\
\end{array}$ & $\begin{array}{c}5.75 \\
3.76-7.34 \\
\end{array}$ & 0.798 \\
\hline ISSI-2 & $\begin{array}{c}304 \\
290-327\end{array}$ & $\begin{array}{c}312 \\
262-375\end{array}$ & $\begin{array}{c}288 \\
241-318\end{array}$ & 0.053 \\
\hline
\end{tabular}

BMI - Body Mass Index; ISSI-2 - Insulin Secretion-Sensitive Index-2; HOMA - Homeostasis Model Assessment

increased risk of overt dysglycaemia could provide significant clinical and economic benefits [20]. Generally, reference intervals are used in the diagnostic process as reference points for the interpretation of the laboratory parameters values obtained for patients who are suspected to have abnormalities $[21,22,23]$. Nonetheless, there is still a lack of adequate procedures for insulin resistance diagnosis, especially in young people, on the basis of appropriate reference intervals. From this aspect, the presented study is important and of 
Table 2. Percentile values for the analyzed indices

\begin{tabular}{lcccc}
\hline \multirow{2}{*}{ Indices } & $\begin{array}{c}\text { th } \\
\text { percentile } \\
95 \% \mathrm{Cl} \\
\mathrm{n}=6\end{array}$ & $\begin{array}{c}\text { 25th } \\
\text { percentile } \\
95 \% \mathrm{Cl} \\
\mathrm{n}=32\end{array}$ & $\begin{array}{c}\text { 75th } \\
\text { percentile } \\
95 \% \mathrm{Cl} \\
\mathrm{n}=97\end{array}$ & $\begin{array}{c}\text { 95th } \\
\text { percentile } \\
95 \% \mathrm{Cl}\end{array}$ \\
\hline \multirow{2}{*}{ HOMA1-IR } & 1.14 & 1.84 & 2.78 & 4.00 \\
& $0.80-1.35$ & $1.77-2.00$ & $2.61-3.10$ & $3.45-4.21$ \\
\hline \multirow{2}{*}{ HOMA2 } & 0.78 & 1.14 & 1.72 & 2.27 \\
& $0.59-0.84$ & $1.08-1.21$ & $1.56-1.79$ & $2.03-2.45$ \\
\hline \multirow{2}{*}{ HOMA2 C-pep. } & 1.16 & 1.53 & 2.63 & 4.10 \\
& $0.89-1.22$ & $1.37-1.66$ & $2.35-3.08$ & $3.64-5.24$ \\
\hline \multirow{2}{*}{ QUICKI } & 0.31 & 0.33 & 0.35 & 0.37 \\
& $0.31-0.32$ & $0.32-0.33$ & $0.34-0.37$ & $0.36-0.4$ \\
\hline \multirow{2}{*}{ Matsuda Index } & 3.19 & 4.31 & 7.48 & 11.33 \\
& $2.37-3.35$ & $3.84-4.64$ & $6.78-8.37$ & $9.96-14.58$ \\
\hline \multirow{2}{*}{ ISSI-2 } & 206 & 261 & 370 & 502 \\
& $181-221$ & $247-269$ & $344-394$ & $441-647$ \\
\hline
\end{tabular}

ISSI-2 - Insulin Secretion-Sensitive Index-2; HOMA - Homeostasis Model Assessment; QUICKI Quantitative Insulin Sensitivity Check Index; $\mathrm{n}$ - number of participants in 5th, 25 th, 75 th and 95 th percentile, respectively.

contemporary relevance. For the purpose of RI introduction, the CLSI recommend establishing the laboratory's own reference intervals dedicated to relevant patient populations (e.g. for the age, gender or clinical condition of the patient), but this is not a routinely used procedure because of the huge labour intensity and financial outlay required. The same documents indicate that individual laboratories should focus on verifying the RI established and provided by manufacturers or published by professional sources [24]. However, the majority of scientific studies provide information about insulin resistance indices values, given as mean or median, while only a few publications concern the determination of reference intervals and/or cut-off values for these indicators, and there are none for age groups similar to the participants studied in the current study.

The largest amount of available information concerns HOMA1-IR in different study groups worldwide. One of the few relevant publications is a study conducted by Yamada et al. [9], who examined HOMA1-IR in a Japanese population in accordance with CLSI protocol. The RIs were calculated as mean $\pm 2 \mathrm{SD}$ and the reference interval yielded $0.4-2.4$, but this value concerned a middle-aged population. Takahara et al. [25] also assessed HOMA1-IR according to the same protocol, and obtained an upper reference limit of 2.4 in middle age, which was different from the value established in the current study. This discrepancy could be due to the higher concentrations of insulin in this study, compared to the Japanese observations caused by cultural diversity, or to different methods of insulin determination [25]. Another study in which the CLSI procedure was applied was conducted by Ramadan in an Egyptian population [26], in which the 97.5th percentile for HOMA1-IR was assessed as 3.5 among males of normal weight and aged $20-69$. An Iranian study conducted by Tohidi et al. [27] is probably the only one in which CLSI recommendations were used to determine the reference interval for QUICKI among non-obese people aged 24-83; the observed 95\% range for this index was $0.33-0.42$. Moreover, the authors assessed reference intervals for HOMA1-IR and HOMA2 as 0.63-2.68, $0.40-1.80$, respectively.

There are many more studies in which the 75th (or 90th) percentile was used to determine the cut-off values for insulin resistance indices. Ascaso et al. [28], studying Spanish people without clinical and biological criteria of IR, established cutoff points for diagnosis of IR as $\geq 3.8$, as the 90th percentile of the observed values. Geloneze et al. [13] set the cut-off values as the 90th percentile in a Brazilian population aged 18-78, and for the HOMA1-IR and HOMA2 indices as 2.7 and 1.8, respectively, for insulin resistance detection. For a Portuguese population with normal fasting glucose and $\mathrm{BMI}<25 \mathrm{~kg} / \mathrm{m}^{2}$ (average age 58.1 years), Timoteo et al. [29] determined the value for HOMA1-IR, and 2.33 was set as the cut-off value for insulin resistance, also as the 90th percentile. In a Scandinavian population aged $24-39$, the most closely related to the group examined in the presented study, the HOMA1-IR, the above upper quartile, was lower than that established in the presented study, and set at levels 1.30 and 1.20 for males and females, respectively [30]. Kwon et al. [31], in a young, healthy population of Koreans aged 20-39, determined the cut-off values for HOMA1-IR for those groups as 2.18 for females and 2.19 for males, using the 75 th percentile. The same authors also assessed the 95th percentile HOMA1-IR in this group as 3.16 and 3.13 for males and females, respectively, but this study was not conducted according to CLSI guidelines, and therefore could not be applied as reference values. The most representative and informative study on insulin resistance in Poland is the research conducted by Szurkowska et al. [10] among people aged 35-75. The authors received the following results for cutoff values for IR recognition: HOMA1-IR> 2.1 (above the 75th percentile) and QUICKI $<0.34$ (below the 25 th percentile), which were similar to those obtained for a younger population in the current study. A similar study was conducted by Radikova et al. [3] for a Caucasian population, where the cut-off values for definite IR, assessed as the 75th percentile for HOMA1-IR and HOMA2, were 2.29 and 1.21, respectively.

There is definitely a smaller amount of research on other indicators of insulin resistance, and at present the authors of this study have found only one study which fulfills the CLSI procedure, conducted by Takahara et al. [25] on a Japanese population with an average age of 49 . The reference interval values for the Matsuda Index were established as $>4.3$, the reference group was chosen on the basis of criteria most closely related to the presented study, but value $>4.3$ was much higher than that obtained in this study as 2.5 th percentile (2.65). For the Caucasian population, there is information only about the Matsuda Index cut-off values examined by Radikova et al. [3], established as 5.0 for the 25th percentile of observed values. A somewhat higher Matsuda Index cut-off value for IR $(<7.3)$ was obtained by Szurkowska et al. [10] for a Polish population aged 35-75.

Regarding ISSI-2, there are no data on reference and/or cut-off values in the available scientific literature. Only Oh et al. [32], among normal glucose tolerance participants, divided on the basis of low or high glucose concentrations at the 60 th min. of OGTT, showed a subsequent mean value of these indices in particular groups: 301.2 for normal glucose tolerance (NGT) and glucose concentration $<155 \mathrm{mg} / \mathrm{dL}$ in the 60 th min. of OGTT and 213.2 for a group of NGT, with a glucose concentration of $\geq 155 \mathrm{mg} / \mathrm{dL}$ at the same time point. The values obtained for the NGT group with low glucose concentration at $60 \mathrm{~min}$. of OGTT were the same as the median observed in the current study.

The data presented above indicates a huge problem with appropriate insulin resistance identification, especially in 
daily clinical practice, due to the lack of clear criteria for the diagnosis of these conditions based on indirect indices of insulin resistance. The use of different criteria for the setting of reference and/or cut-off values determines the achievement of different IR recognition frequencies. It should be emphasized that the CLSI protocol used in the current study for establishing reference intervals is still not widely used in laboratory medicine. Therefore, the authors decided to discuss the results of their study as results observed for the 6th and 123rd ranked patients' values, which correspond to the 5th and 95th percentiles according to CLSI protocol, as well as the results observed in the 32 th and 97 th ranked patients, which correspond to the 25 th and 75 th of all 130 participants included in the analysis for the purposes of comparison with data in the literature. This is indicated by the importance of the use of unified, recommended criteria to determine these values. As provided by the data from the literature, the values of IR indices might also differ between nations, because heterogeneity in ethnicity contributes to discrepancies in the degree of insulin resistance. However, it is unreasonable to directly compare these studies unless HOMA1-IR reference limits are determined by a standardized procedure [9]. The interchangeable use of cut-offs (established as the 75th or 90 th percentile) and reference intervals, causes discrepancies in the interpretation and adoption of appropriate indice values, and it is therefore invariably important to use the same procedures, e.g. according to the CLSI. Establishing reference intervals in a similar way to their use in this study will facilitate the use of insulin resistance indices in routine clinical practice. This approach will enable the accurate identification of individuals at risk of metabolic diseases and the development of personalized therapeutic interventions.

Study limitations. The authors are aware of the basic limitations of the presented study with regard to the laboratory methods used. While glucose methodology is almost perfectly standardized, the methods of insulin determination used in laboratories are very diverse, which is very much due to the lack of an international standard. For this reason, the trimmed-out reference limit has an application in laboratories using the same methodology. Another significant disadvantage is the limited number of participants in the study, particularly in relation to the male group, which was due to the much lower reporting of males during the study. The narrow age range of study participants also limited the use of the reference intervals of the analyzed indices established. However, the young age of participants in this study could also be counted as an advantage, because to the best of the knowledge of the authors, no such extensive publications on insulin resistance indices concerning this age group exist.

\section{CONCLUSIONS}

The reference intervals obtained, when applying the same laboratory methods for HOMA1-IR $\leq 4.00$, HOMA2 $\leq 2.27$, HOMA2 C-pep. $\leq 4.10$, QUICKI $\geq 0.31$, Matsuda Index $\geq 3.19$ and ISSI- $2 \geq 206$, can be used for recognition of insulin resistance, reduced insulin sensitivity and decreased ability of the pancreas beta cell, respectively, in a Polish population aged 18-31. Establishing cut-off values for these indices is significant regarding the possibility of comparing results with those of other authors, due to the scant information about reference values in epidemiological studies. To the best of the authors' knowledge, this is the first reference interval study of indirect insulin resistance indices for a young Polish population, which follows the stringent CLSI document. This is especially important for clinical practice, due to the lack of appropriate guidelines dedicated to this age group. For this reason, it is crucial to determine the indicator RIs relative to populations and particular medical laboratories. In order to improve the diagnostic process of insulin resistance recognition, population studies should be performed and the reference intervals and decision limits for insulin resistance, insulin sensitivity and pancreatic beta cell function for different age groups should be determined.

\section{Acknowledgement}

This study was supported by the Wroclaw Medical University under Grant ST-D160.16.016.

\section{REFERENCES}

1. Gutch M, Kumar S, Razi SM, Gupta KK, Gupta A. Assessment of insulin sensitivity/resistance. Indian J Endocrinol Metab. 2015; 19(1): 160-4. http://doi.org/10.4103/2230-8210.146874

2. Sung KC, Jeong WS, Wild SH, Byrne CD. Combined influence of insulin resistance, overweight/obesity, and fatty liver as risk factors for type 2 diabetes. Diabetes Care. 2012; 35(4): 717-22. htpp://doi: $10.2337 / \mathrm{dc1} 1-1853$.

3. Radikova Z, Koska J, Huckova M, Ksinantova L, Imrich R, Vigas $\mathrm{M}$, et al. Insulin sensitivity indices: a proposal of cut-off points for simple identification of insulin-resistant subjects. Exp Clin Endocrinol Diabetes. 2006; 114(5): 249-56. http://doi.org/10.1055/s-2006-924233.

4. Zhang Y, Fu J, Yang S, Yang M, Liu A, Wang L, et al. Prevalence of metabolically obese but normal weight (MONW) and metabolically healthy but obese (MHO) in Chinese Beijing urban subjects. Biosci Trends. 2017; 11(4): 418-26. http://doi.org/10.5582/bst.2017.01016

5. Tam CS, Xie W, Johnson WD, Cefalu WT, Redman LM, Ravussin E. Defining insulin resistance from hyperinsulinemic-euglycemic clamps. Diabetes Care. 2012; 35(7): 1605-10. http://org/doi:10.2337/dc11-2339

6. Oka R, Yagi K, Sakurai M, Nakamura K, Moriuchi T, Miyamoto S, et al. Insulin secretion and insulin sensitivity on the oral glucose tolerance test (OGTT) in middle-aged Japanese. Endocr J. 2012; 59(1): 55-64. https://doi.org/10.1507/endocrj.EJ11-0157

7. Matthews DR, Hosker JP, Rudenski AS, Naylor BA, Treacher DF, Turner RC. Homeostasis model assessment: insulin resistance and beta-cell function from fasting plasma glucose and insulin concentrations in man. Diabetologia. 1985; 28(7): 412-9.

8. Abdul-Ghani MA, DeFronzo RA. Pathogenesis of Insulin Resistance in skeletal muscle. J Biomed Biotechnol. 2010; http://doi. org/10.1155/2010/476279.

9. Yamada C, Mitsuhashi T, Hiratsuka N, Inabe F, Araida N, Takahashi E. Optimal reference interval for homeostasis model assessment of insulin resistance in a Japanese population. J Diabetes Investig. 2011; 2(5): 373-6. http://doi.org/10.1111/j.2040-1124.2011.00113.x

10. Szurkowska M, Szafraniec K, Gilis-Januszewska A, Szybinski Z, Huszno B. Insulin resistance indices in population-based study and their predictive value in defining metabolic syndrome. Przegl Epidemiol. 2005; 59(3): 743-51.

11. Płaczkowska S, Kokot I, Pawlik-Sobecka L, Kołaczek A, Małolepsza E. Indices of insulin resistance in Wroclaw university students Preliminary report. Fam Med Primary Care Rev. 2013; 15(3): 370-1.

12. Stankiewicz-Olczyk J, Bolanowski M, Milewicz A, JawiarczykPrzybyłowska A. The prevalence of metabolic syndrome in economically active men. Endokrynol Otyłość. 2012; 8(2): 59-64.

13. Geloneze B, Vasques AC, Stabe CF, Pareja JC, Rosado LE, Queiroz EC, et al. HOMA1-IR and HOMA2-IR indexes in identifying insulin resistance and metabolic syndrome: Brazilian Metabolic Syndrome Study (BRAMS). Arq Bras Endocrinol Metabol. 2009; 53(2): 281-7. http://doi.org/10.1590/S0004-27302009000200020

14. Katz A, Nambi SS, Mather K, Baron AD, Follmann DA, Sullivan G, et al. Quantitative insulin sensitivity check index: a simple, accurate 
method for assessing insulin sensitivity in humans. J Clin Endocrino Metab. 2000; 85(7): 2402-10. http://doi.org/10.1210/jcem.85.7.6661.

15. Matsuda M, DeFronzo RA. Insulin sensitivity indices obtained from oral glucose tolerance testing: comparison with the euglycemic insulin clamp. Diabetes Care. 1999 Sep; 22(9): 1462-70. https://doi.org/10.2337/ diacare.22.9.1462

16. Retnakaran R, Qi Y, Goran MI, Hamilton JK. Evaluation of proposed oral disposition index measures in relation to the actual disposition index. Diabet Med. 2009; 26(12): 1198-203. http://doi.org/10.1111/ j.1464-5491.2009.02841.x.

17. CLSI. Defining, Establishing, and Verifying Reference Intervals in the Clinical Laboratory; Approved Guideline-Third Edition. CLSI document C28-A3. Wayne, PA: Clinical and Laboratory Standards Institute; 2008.

18. Płaczkowska S, Pawlik-Sobecka L, Kokot I, Piwowar A. Estimation of metabolic factors related to insulin resistance and metabolic syndrome in young people. Scand J Clin Lab Invest. 2018. http://doi.org/10.1080 /00365513.2018.1469787.

19. WEB calculator. Available at: http://mmatsuda.diabetes-smc.jp/english. html. Accessed September 27th, 2017.

20. Dankner R, Chetrit A, Shanik MH, Raz I, Roth J. Basal-state hyperinsulinemia in healthy normoglycemic adults is predictive of type 2 diabetes over a 24-year follow-up: a preliminary report. Diabetes Care. 2009; 32(8): 1464-6. http://doi.org/10.2337/dc09-0153

21. Siest G, Henny J, Ralph Grasbeck R, Wilding P, Petitclerc C, et al. The theory of reference values: an unfinished symphony. Clin Chem Lab Med. 2013; 51(1): 47-64. http://doi.org/10.1515/cclm-2012-0682.

22. Boyd JC. Defining laboratory reference values and decision limits: populations, intervals, and interpretations. Asian J Androl. 2010; 12: 83-90. http://doi.org/10.1038/aja.2009.9.

23. Ozarda Y. Reference intervals: current status, recent developments and future considerations. Biochem Med. 2016; 26(1): 5-16. http://doi. org/10.11613/BM.2016.001

24. Appold K. Determining Laboratory Reference Intervals: CLSI Guideline Makes the Task Manageable. Lab Med. 2009; 40(2): 75-6. https://doi. org/10.1309/LMEHV3HP39QOFJPA

25. Takahara M, Katakami N, Kaneto H, Noguchi M, Shimomura I. Distribution of the Matsuda Index in Japanese healthy subjects. J Diabetes Investig 2013; 4(4): 369-71. http://doi.org/10.1111/jdi.12056.
26. Ramadan RA. Establishment of Reference Interval for Homeostasis Model Assessment of Insulin Resistance in Healthy Adult Males: a Pilot Study in Alexandria Governorate, Egypt. Iran J Diabetes and Obes. 2013; 5(3): 91-7.

27. Tohidi M, Ghasemi A, Hadaegh F, Derakhshan A, Chary A, Azizi F. Age-and sex-specific reference values for fasting serum insulin levels and insulin resistance/sensitivity indices in healthy Iranian adults: Tehran Lipid and Glucose Study. Clin Biochem. 2014; 47(6): 432-8. http://doi.org/10.1016/j.clinbiochem.2014.02.007

28. Ascaso JF, Romero P, Real JT, Priego A, Valdecabres C, Carmena R. Insulin resistance quantification by fasting insulin plasma values and HOMA index in a non-diabetic population. Med Clin (Barc). 2001; 117(14): 530-3.

29. Timoteo AT, Miranda F, Carmo MM, Ferreira RC. Optimal cut-off value for homeostasis model assessment (HOMA) index of insulinresistance in a population of patients admitted electively in a Portuguese cardiology ward. Acta Med Port. 2014; 27(4): 473-9.

30. Wurtz P, Makinen VP, Soininen P, Kangas AJ, Tukiainen T, Kettunen J, et al. Metabolic signatures of insulin resistance in 7,098 young adults. Diabetes. 2012; 61(6): 1372-80. http://doi.org/10.2337/db11-1355.

31. Kwon SS, Lee SG, Lee YH, Lim JB, Kim JH. Homeostasis model assessment of insulin resistance in a general adult population in Korea: additive association of sarcopenia and obesity with insulin resistance. Clin Endocrinol (Oxf). 2017; 86(1): 44-51. http://doi.org/10.1111/ cen.13233.

32. Oh TJ, Min SH, Ahn CH, Kim EK, Kwak SH, Jung HS, et al. Normal Glucose Tolerance with a High 1-Hour Postload Plasma Glucose Level Exhibits Decreased beta-Cell Function Similar to Impaired Glucose Tolerance. Diabetes Metab J. 2015; 39(2): 147-53.

33. Alberti KG, Eckel RH, Grundy SM, Zimmet PZ, Cleeman JI, Donato $\mathrm{KA}$, et al.Harmonizing the metabolic syndrome: A joint interim statement of the international diabetes federation task force on epidemiology and prevention; National heart, lung, and blood institute; American heart association; World heart federation; International atherosclerosis society; And international association for the study of obesity. Circulation. 2009; 120(16): 1640-5. 